\title{
HMG-CoA Lyase Deficiency
}

National Cancer Institute

\section{Source}

National Cancer Institute. HMG-CoA Lyase Deficiency. NCI Thesaurus. Code C84523.

A rare genetic inherited disorder characterized by inability of the body to process the amino acid leucine. Signs and symptoms include vomiting, dehydration, lethargy, convulsions, and coma. 